\title{
Structural, economic and material comparison of various steel grades under dynamic/fatigue loading
}

\author{
I. U. Amobi \& H. C. Uzoegbo \\ School of Civil and Environmental Engineering, \\ University of the Witwatersrand, Johannesburg, South Africa
}

\begin{abstract}
As industries are upgrading rapidly from a lower steel grade to higher ones it has become necessary to study the effect of changing from lower steel grades to higher grades. This paper reports on fatigue life and behaviour, economic implications and material composition of these higher strength steels (HSS) as compared to the conventional grades. Three grades are commercially available in South Africa: 300W, 350W and 460W. These different steel grades (conventional and HSS) with the same moment capacities were subjected to constant dynamic stresses and the fatigue crack growth of the overloading and unloading were monitored and compared with each other. The influences of the overloading and unloading made standard grades perform better under repeated loading than the HSS, since HSS have been proved to have poor ductility, resulting in a lower number of cycles to failure. An $85 \%$ increase in material cost was generated as HSS replaces the conventional lower steel grades. A reduction in the number of cycles to failure in HSS was over $500 \%$.

Keywords: steel grade, HSS, fatigue, low-cycle fatigue, high-cycle fatigue, load capacity, cycles to failure.
\end{abstract}

\section{Introduction}

There is a trend towards increasing the strength grade of the general purpose steel for construction in most countries. This trend was prompted by increased loading on structures, larger spans and architectural designs that require smaller sections. Australia and other countries around the world have in recent years changed from lower steel grades to higher ones. In 2005, South Africa changed 
from grade $300 \mathrm{~W}$ steel to grade $350 \mathrm{~W}$ steel. The current investigation is mainly concerned with the study of the dynamic behaviour of the three main grades in South Africa.

\section{Specimen section determination and Loading}

Since various steel grades $(300 \mathrm{~W}, 350 \mathrm{~W}$ and $460 \mathrm{~W})$ were tested under the same conditions, the load capacities of these steel grades were designed to be equal. To achieve this, an initial I-section of the $300 \mathrm{~W}$ grade was assumed and its load capacity determined. The load capacity was then imposed on the other sections, $350 \mathrm{~W}$ and $460 \mathrm{~W}$, and their different sections determined.

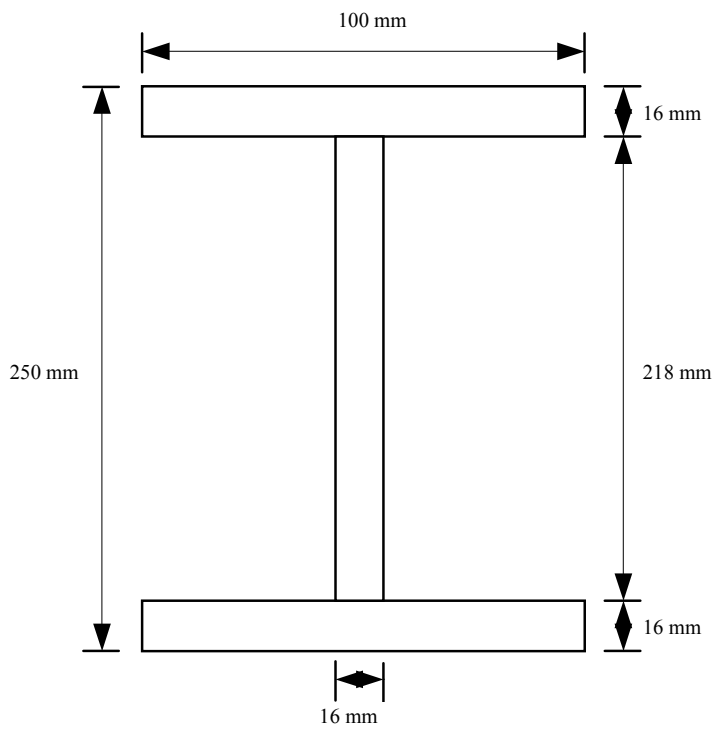

Figure 1: Initial 300W section.

In order to maintain consistency, only the overall depth $\mathrm{d}$, of the initial section grade was changed to suit the equivalent load capacity of grades $350 \mathrm{~W}$ and $460 \mathrm{~W}$. As a result, the equation for the section modulus, $\mathrm{Z}_{\mathrm{pl}}$ became:

$$
Z_{p l}=\left[\frac{100 x d^{2}}{4}\right]-2\left[\frac{42 x(d-32)^{2}}{4}\right]
$$

As $\mathrm{d}=250 \mathrm{~mm}$ for the initial section grade, the moment capacity was easily determined from the following equation:

$$
M_{p}=0.9 x Z_{p l} x f_{y}
$$


The moment capacity was then imposed on $350 \mathrm{~W}$ and $460 \mathrm{~W}$ accordingly and their respective overall depths were determined. A summary of the section dimensions is shown in the following table below:

The samples are assumed to be laterally supported. Plates with $16 \mathrm{~mm}$ thickness were ordered in all three grades. The samples were factory fabricated to specification and delivered to the laboratory for testing.

Table 1: $\quad$ Section dimensions of the various grades.

\begin{tabular}{|l|c|c|c|}
\hline \multicolumn{1}{|c|}{ Specimen } & $300 \mathrm{~W}$ & $350 \mathrm{~W}$ & $460 \mathrm{~W}$ \\
\hline $\begin{array}{l}\text { Breadth of top } \\
\text { flange, } b_{\mathrm{tf}}\end{array}$ & $100 \mathrm{~mm}$ & $100 \mathrm{~mm}$ & $100 \mathrm{~mm}$ \\
\hline $\begin{array}{l}\text { Breadth of bottom } \\
\text { flange, } b_{\mathrm{bf}}\end{array}$ & $100 \mathrm{~mm}$ & $100 \mathrm{~mm}$ & $100 \mathrm{~mm}$ \\
\hline $\begin{array}{l}\text { Depth of top } \\
\text { flange, } \mathrm{t}_{\mathrm{ff}}\end{array}$ & $16 \mathrm{~mm}$ & $16 \mathrm{~mm}$ & $16 \mathrm{~mm}$ \\
\hline $\begin{array}{l}\text { Depth of bottom } \\
\text { flange, } \mathrm{t}_{\mathrm{bf}}\end{array}$ & $16 \mathrm{~mm}$ & $16 \mathrm{~mm}$ & $16 \mathrm{~mm}$ \\
\hline $\begin{array}{l}\text { Length of top } \\
\text { flange, } \mathrm{l}_{\mathrm{tf}}\end{array}$ & $2500 \mathrm{~mm}$ & $2500 \mathrm{~mm}$ & $2500 \mathrm{~mm}$ \\
\hline $\begin{array}{l}\text { Length of bottom } \\
\text { flange, } \mathrm{l}_{\mathrm{bf}}\end{array}$ & $2500 \mathrm{~mm}$ & $2500 \mathrm{~mm}$ & $2500 \mathrm{~mm}$ \\
\hline $\begin{array}{l}\text { Breadth of web, } \\
\mathrm{b}_{\mathrm{w}}\end{array}$ & $16 \mathrm{~mm}$ & $16 \mathrm{~mm}$ & $16 \mathrm{~mm}$ \\
\hline Depth of web, $\mathrm{t}_{\mathrm{w}}$ & $218 \mathrm{~mm}$ & $193 \mathrm{~mm}$ & $155 \mathrm{~mm}$ \\
\hline Length of web, $1_{\mathrm{w}}$ & $2500 \mathrm{~mm}$ & $2500 \mathrm{~mm}$ & $2500 \mathrm{~mm}$ \\
\hline Overall Depth, $\mathrm{d}$ & $250 \mathrm{~mm}$ & $225 \mathrm{~mm}$ & $187 \mathrm{~mm}$ \\
\hline
\end{tabular}

\subsection{Instrumentation}

The setup was done in such a way that a constant force was maintained throughout each experiment and the strain measurements were periodically taken. A $100 \mathrm{~mm}$ LVDT which was firmly fixed to the specimen was connected serially to both the DC voltage power supply and the memory card of an 'Agilent' Data Logger in order that voltage output can be measured during testing.

The data logger was then connected to a computer which has the Agilent programme installed in order that the measurements can be adjusted and stored appropriately.

Although the setup was not based on maximum deflection method but rather on force method, the LVDT was firmly fixed at mid-span directly under the 
point of load application. This enables us to ascertain the behaviour of the various specimens under specific loadings. Strain gauges were precisely glued at various sensitive places on the specimen and connected to a strain gauge reader.

Since the MTS actuator measures its capacity in percentages, a load calibrator was used to convert the load percentage to actual readable loading quantities.

\subsection{Loading}

There were two specimens for each grade of steel and two loading capacities for these various grades of steel. The specimens were tested under the same constant load as tabulated below. The load was applied at mid-span for all cases and supported at the supports. Proper bracings were provided in order to avoid lateral displacement. The applied loads were expressed as a percentage of the static load capacity of the sections.

Table 2: $\quad$ Load capacities.

\begin{tabular}{|c|l|l|}
\hline Steel Grade & Cyclic Load 1 & Cyclic Load 2 \\
\hline $300 \mathrm{~W}$ & $0.50 \mathrm{P}=122 \mathrm{kN}$ & $0.75 \mathrm{P}=184 \mathrm{kN}$ \\
\hline $350 \mathrm{~W}$ & $0.50 \mathrm{P}=122 \mathrm{kN}$ & $0.75 \mathrm{P}=184 \mathrm{kN}$ \\
\hline $460 \mathrm{~W}$ & $0.50 \mathrm{P}=122 \mathrm{kN}$ & $0.75 \mathrm{P}=184 \mathrm{kN}$ \\
\hline
\end{tabular}

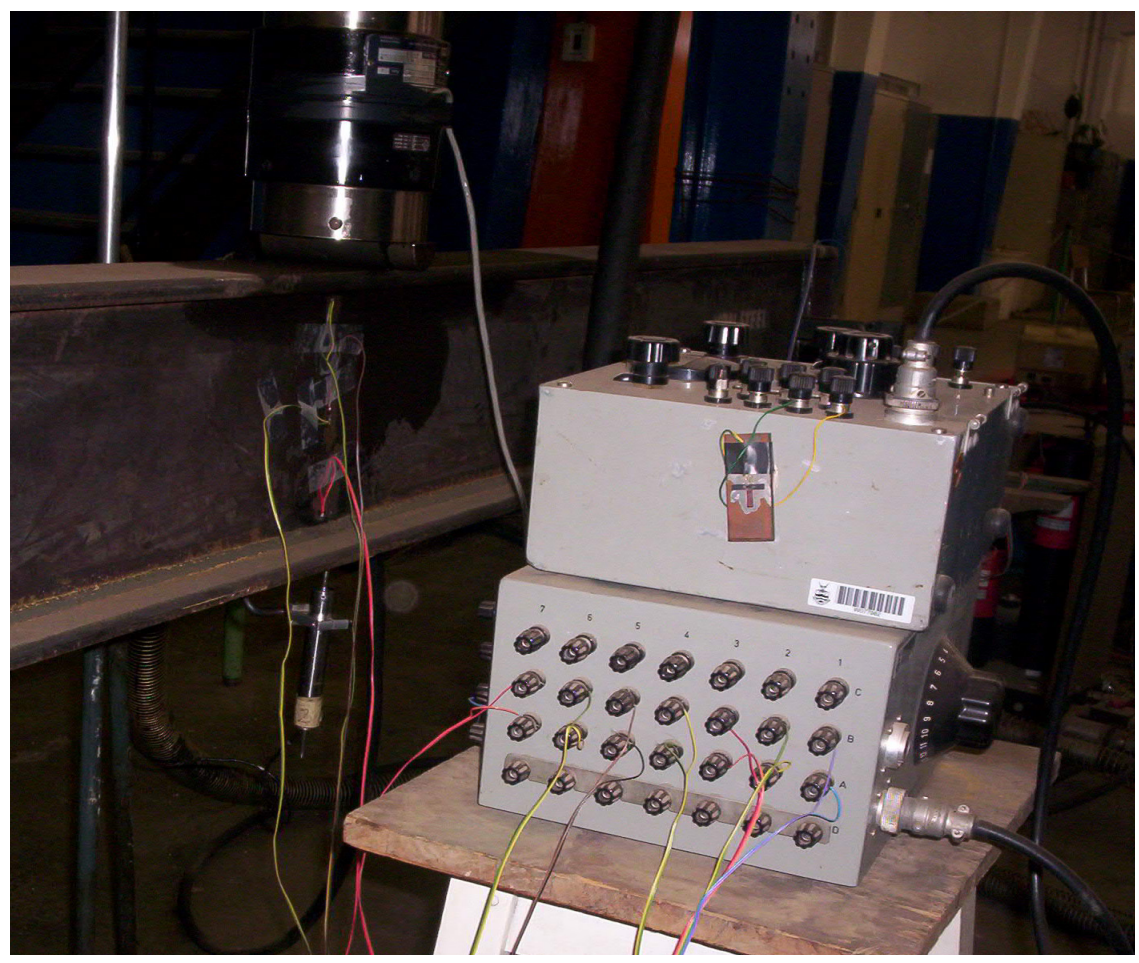

Figure 2: $\quad$ Test setup. 


\section{Results}

Due to varying section compositions, the stresses generated at particular points were peculiar to each specimen. The strain values at support and zone of loading were measured after every 100,000 cycles at a frequency of $1 \mathrm{~Hz}$ using strain gauges. The stresses generated at the mid-span until failure is shown in the table below:

Table 3: $\quad$ Mid-span stresses during failure.

\begin{tabular}{|c|c|}
\hline Specimen loading & Stress generated $\left(\mathrm{N} / \mathrm{mm}^{2}\right)$ \\
\hline $300 \mathrm{~W} @ 122 \mathrm{kN}$ & 165 \\
\hline $350 \mathrm{~W} @ 122 \mathrm{kN}$ & 192 \\
\hline $460 \mathrm{~W} @ 122 \mathrm{kN}$ & 251 \\
\hline $300 \mathrm{~W} @ 184 \mathrm{kN}$ & 249 \\
\hline $350 \mathrm{~W} @ 184 \mathrm{kN}$ & 290 \\
\hline $460 \mathrm{~W} @ 184 \mathrm{kN}$ & 378 \\
\hline
\end{tabular}

Top Flange of 300W @ 122KN

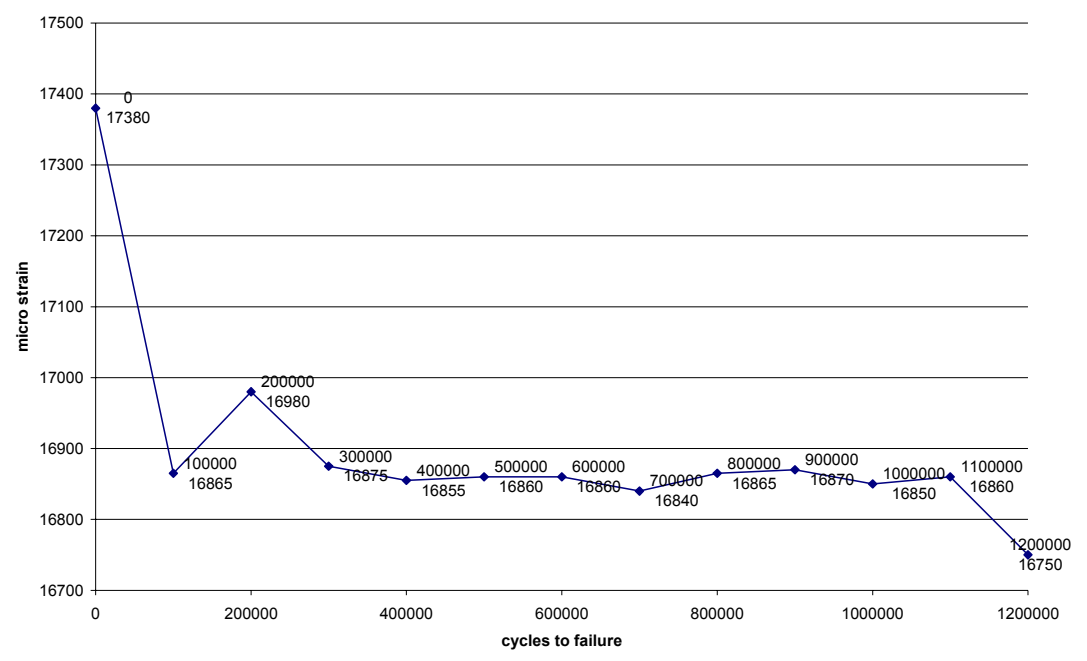

Figure 3: $\quad$ Microstrain result for top flange.

The stresses were constant until failure occurred. Since there were no changes in stresses, i.e. a constant stress was applied to the structure throughout the testing until failure; the stress-strain curve yielded a straight line.

The changes in strain were monitored periodically during the life of the experiment. Microstrains were read off at every 100,000 cycles of loading. The behaviour of strain with respect to the number of cycles occurred in the same pattern for all cases. For the microstrain at the top flange, there was a sharp 
contraction after the first 100,000 cycles and afterwards stabilization, showing that the top flange was under compression.

For the microstrain in the web, there was a sharp increment of the specimen at the web as measured using the strain gauges. This shows that the web was under tension. Its behaviour was constant for all specimens, although the values were varying due to different loading for each specimen. Figures 1 and 2 show a consistent pattern of the microstrain results with respect to cycles to failure.

Figures 3 and 4 are results for $300 \mathrm{~W}$ at $122 \mathrm{kN}$. For the other experiments, the graph curve remains constant but with varying results at all points.

Web - D of 300W @ 122KN cyclic loading

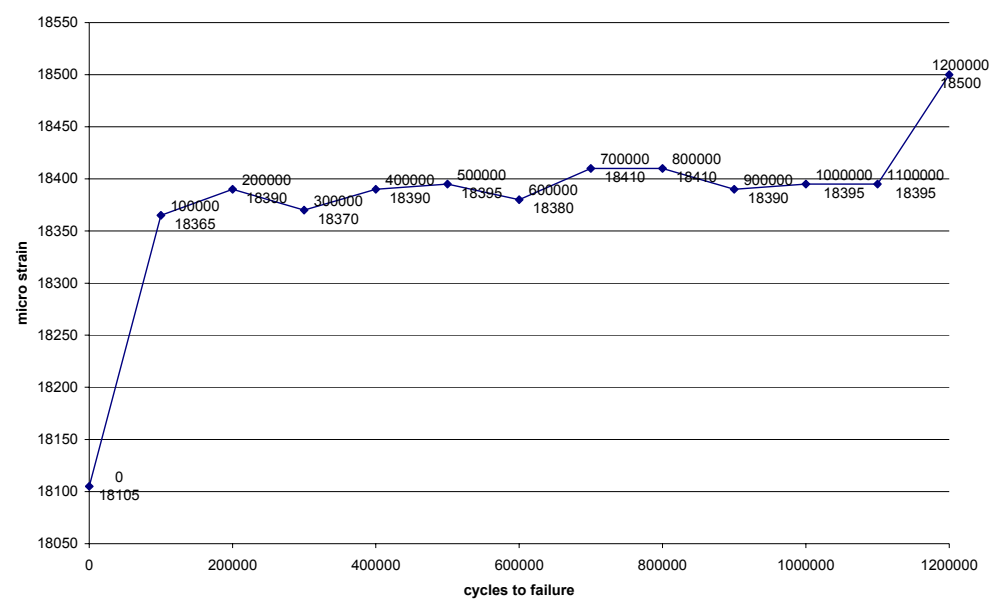

Figure 4: Microstrain result for web.

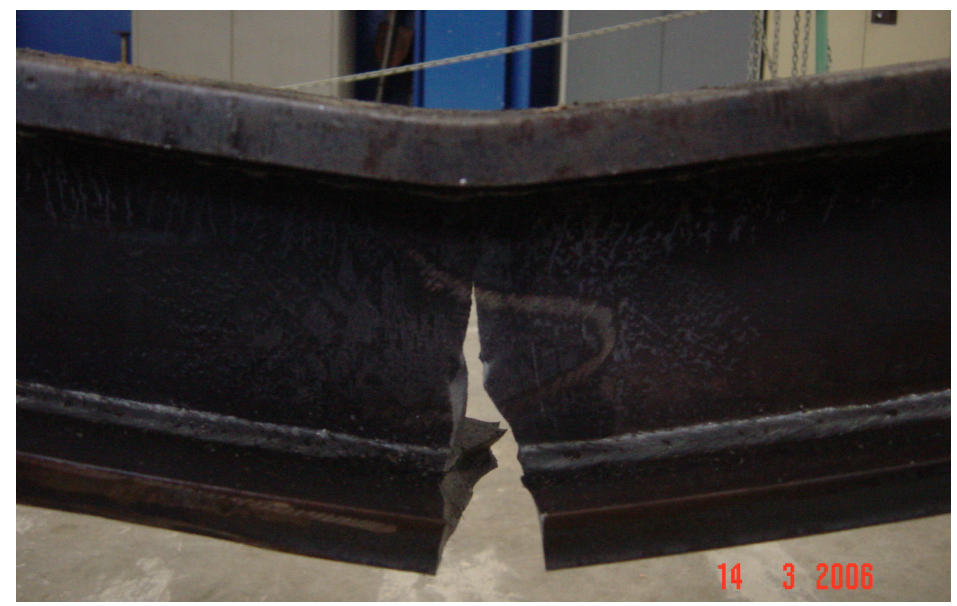

Figure 5: $\quad$ Failed beam. 
There were several initiations of micro-cracks which eventually grew and formed one macro-crack that caused instant fracture of the beams. Failure occurred instantaneously without warning because the beams where tested within their elastic region. When the beams were unloaded, they returned to their original form without any visual deformation.

\subsection{Discussions}

It is observed that as the steel grades increase in yield stress with lower web depth, their cycle to failure reduces. As a wrap up, the tables below show in summary the points of failure for the various steel grades tested under the same load factor.

Table 4: $\quad$ Under $0.5 \mathrm{P}=122 \mathrm{kN}$.

\begin{tabular}{|c|c|c|}
\hline Steel Grades & Failure Cycle & Testing Time \\
\hline $300 \mathrm{~W}$ & $1,200,000$ & 333 hours \\
\hline $350 \mathrm{~W}$ & 786,000 & 218 hours \\
\hline $460 \mathrm{~W}$ & 182,400 & 51 hours \\
\hline
\end{tabular}

Table 5: $\quad$ Under $0.75 \mathrm{P}=184 \mathrm{kN}$.

\begin{tabular}{|c|c|c|}
\hline Steel Grades & Failure Cycle & Testing Time \\
\hline $300 \mathrm{~W}$ & 322,023 & 89 hours \\
\hline $350 \mathrm{~W}$ & 60 & 1 minute \\
\hline $460 \mathrm{~W}$ & 50 & 50 seconds \\
\hline
\end{tabular}

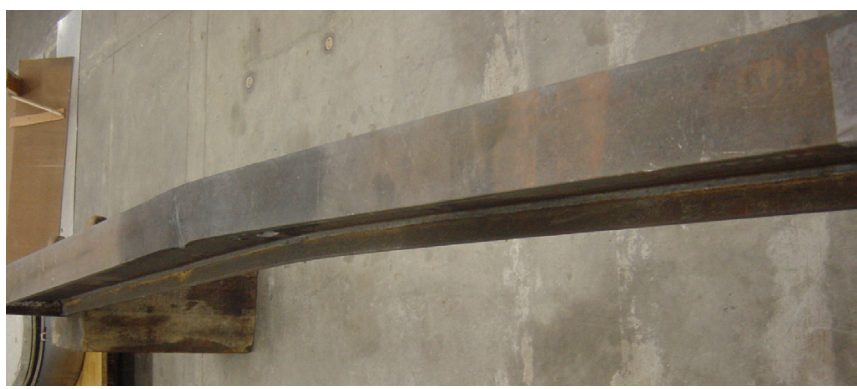

Figure 6: $\quad$ Failed beam. 
Grades $350 \mathrm{~W}$ and $460 \mathrm{~W}$ failed by deformation under $75 \%$ of their capacity indicating poor ductility in material composition. All the specimens failed, whether fracture or deformation, within the zone of loading. The stresses induced at the point of failure where close to the maximum stresses induced at the midspan of the specimens. Even for specimen 1 (300W@122 kN) which failed by global buckling, the maximum deformation occurred at the zone of loading.

\subsubsection{Structural consideration}

From tables 4 and 5 above, we can conclude that an increase in the steel grade reduces the capacity for the steel to withstand fatigue loading. The experiment shows clearly a reduction in cycles to failure as the steel grades increase. This statement can be shown graphically in the following graph.

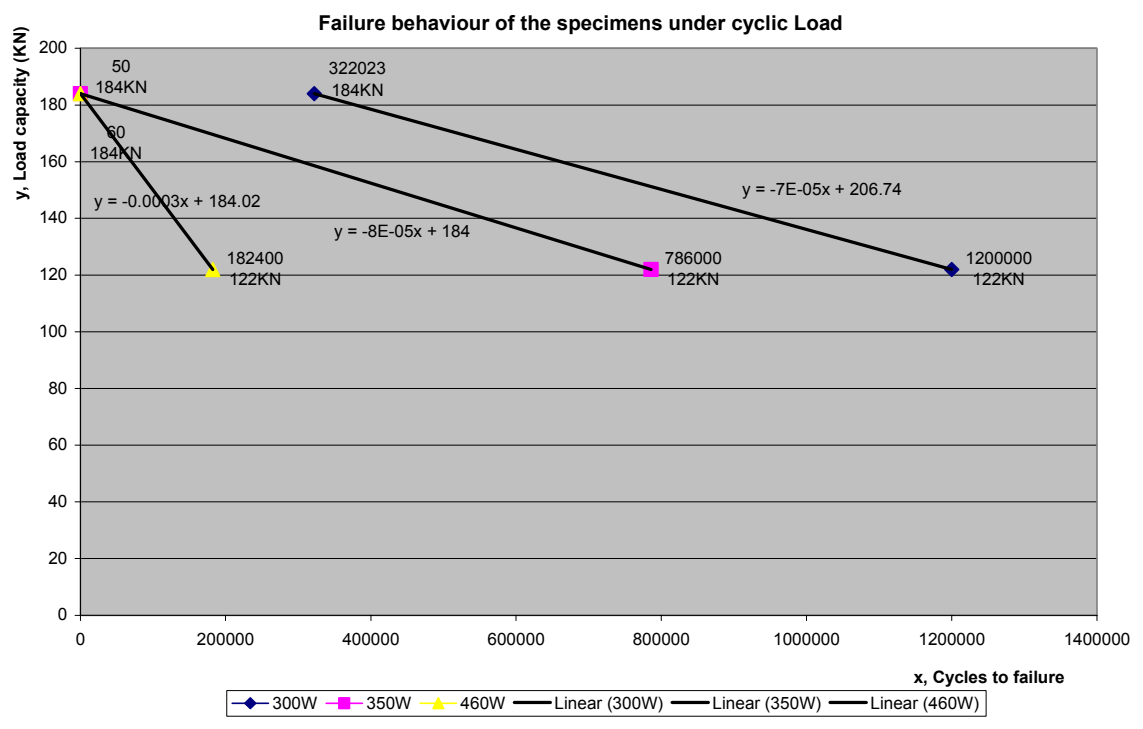

Figure 7: $\quad$ Failure behaviour of specimens under cyclic loading.

Graphic equations were derived from the results in order that predictions for various load capacities of the steel grades can be fairly determined. The graph showed a linear relationship because only two load capacities for each steel grade were tested. As a result, estimations for cycles to failure of various load capacities can only be done within the limits of the experiment.

For $300 W, y=-7 x 10-05 x+206.64$

For $350 \mathrm{~W}, \mathrm{y}=-8 \mathrm{x} 10-05 \mathrm{x}+184$

For $460 \mathrm{~W}, \mathrm{y}=-0.0003 \mathrm{x}+184.02$

Where $\mathrm{x}=$ Cycles to failure and $\mathrm{y}=$ Load capacity in $\mathrm{kN}$ Range: $122 \mathrm{kN}<\mathrm{y}<184 \mathrm{kN}$

A fair idea of the cycles to failure for any grade of steel can easily be determined for any load capacity or stress, provided they are within the ranges given. 


\subsubsection{Economic consideration}

The costs per kilogram of various steel grades in South Africa are listed in the table below:

Table 6: Cost of the various steel grades.

\begin{tabular}{|c|c|c|c|}
\hline Specimen & $300 \mathrm{~W}$ & $350 \mathrm{~W}$ & $460 \mathrm{~W}$ \\
\hline Cost per kg (Rands) & 5.50 & 6.50 & 12.00 \\
\hline
\end{tabular}

For the specimens tested, the cost of $300 \mathrm{~W}$ which is $130.4 \mathrm{~kg}$ is equivalent to $\mathrm{R} 717.20$, the cost of $350 \mathrm{~W}$ which gave a mass of $122.62 \mathrm{~kg}$ is equivalent to R797.03 and 460W (110.7 kg) gave a cost of R1329.12.

As a result of the price comparison, the will be an $11 \%$ increase in the cost of steel material when converting from $300 \mathrm{~W}$ to $350 \mathrm{~W}$ and an $85 \%$ increase when converting from $350 \mathrm{~W}$ to $460 \mathrm{~W}$ steel grade for the erection of any structure. Considering a structure that involves hundreds of metres of steel, an $11 \%$ or $85 \%$ increment in material cost will definitely become uneconomical.

\subsection{Conclusion}

Although HSS is $30 \%$ thinner, $30 \%$ lighter and with a doubled strength, a well refined grain size and easily maintained, it is still poor in withstanding fatigue loading and highly uneconomical when compared with conventional grades.

\section{References}

[1] M.A. Gizejowski, H.C. Uzoegbo and A. Kozlowski, Selection Criteria for a general purpose construction steel strength grade, Conf. Proc. $2^{\text {nd }}$ International conference on the African Materials Society (MRS), 2003.

[2] A. Koursaris and F.O. Nghoudzweni, Fatigue determination of full-scale Aluminium I-beams. 2002.

[3] M. Skaloud and M. Zornorova, The Fatigue life of steel plate girders subjected to repeated loading. Proc. Of the Slovenke Konference, pp. 403408, 2003.

[4] R. Maquoi and M. Skaloud, Some remarks in regard to the fatigue analysis of steel plate girders with breathing webs. Proc. Of the Slovenke Konference, pp. 397-402, 2003. 